\title{
Effect of residual stress on the fracture of chemically strengthened thin aluminosilicate glass
}

Liangbao Jiang ${ }^{1,2^{*}}$, Yi Wang ${ }^{2}$, Iman Mohagheghian ${ }^{2}$, Xiaoyu $\mathrm{Li}^{1}$, Xintao Guo ${ }^{1}$, Lei

$$
\mathrm{Li}^{1} \text {, John P Dear }{ }^{2 *} \text {, Yue Yan }{ }^{1 *}
$$

${ }^{1}$ Beijing Institute of Aeronautical Materials, Beijing 100095, China;

${ }^{2}$ Department of Mechanical Engineering, Imperial College London, South

Kensington Campus, London, SW7 2AZ, United Kingdom

*Corresponding authors, Tel: +861062496511, Fax: +861062497654.

Email: liangbaojiang@hotmail.com (L. Jiang), j.dear@imperial.ac.uk (J. Dear) and yue.yan@biam.ac.cn (Y. Yan) 


\begin{abstract}
The effect of residual stress on the fracture of chemically strengthened thin aluminosilicate glass was investigated. The large deflection problem on the flexure of thin chemically strengthened glass was solved through finite element analysis. The relationship among compressive stress (CS), central tension (CT), and the modulus of rupture of chemically strengthened thin glass was also discussed. High CS and low CT improved the flexural strength of chemically strengthened glass. However, the effect of residual stress was more complex on Weibull modulus than on strength. The effect of residual stress on the fractography of chemically strengthened thin glass was analyzed. Transparent and opaque zones were observed on the fracture surface of chemically strengthened glass. The relative thickness of the opaque zone ( $\left.\mathrm{d}_{\text {Opaque }} / \mathrm{d}_{0}\right)$, which is a constant in the same fracture zone, linearly decreased with increasing fracture zone. This result indicates that the stored elastic strain energy was released with the number of transverse cracks. These results provide useful information on the failure analysis of chemically strengthened thin glass.
\end{abstract}

\title{
Key words
}

Chemically strengthened glass; Residual stress; Large deflection; Fracture 


\section{Introduction}

Chemical strengthening is an effective method of strengthening thin glass; during this process, thin glasses are immersed in a molten alkali salt at a temperature below the glass transition [1]. $\mathrm{K}^{+}-\mathrm{Na}^{+}$ion exchange, which was introduced by Kistler in 1962, is the most commonly described route of chemical strengthening [2]. Strengthening has two competing processes: one is the generation of stress from "stuffing" large foreign ions into small host ion sites in the glass, and the other is the relaxation of stress using viscous flow [3]. The exchange depth, the concentration of ions that can be replaced with large ions, and any stress or structural relaxation that may occur determine the magnitudes of the residual stress. For a given thickness of glass, the residual stress is varied by compressive stress (CS), central tension (CT) and the depth of stress layer (DOL)[4]. The improvement of strength is contributed from residual stress profile in chemically strengthened glass. Therefore, understanding the effect of residual stress on the fracture of glass is not only of long-standing fundamental interest but is also important for controlling the mechanical properties of glass products.

The ring-on-ring (ROR) test is commonly used to evaluate the strength of a monolithic glass substrate. The linear bending of glass in ROR fixtures is well known and formulated in ASTM standards [5, 6]. However, these standards restrict the deflection to one quarter of the glass thickness. If the uncommon small-deflection theory is considered, then the strength value obtained would be significantly high because the membrane stress from the large deflection is neglected. Consequently, the 
rigorous large-deflection theory is required to convert failure load to failure stress (strength) of a glass substrate [7-9].

The nature of fracture in chemically strengthened glass determines the safety degree of the glass. Fracture mechanics provide the context for understanding the fracture of brittle materials, including glass $[10,11]$. A crack in glass begins to grow when the crack-tip stress intensity factor $\mathrm{K}_{\mathrm{I}}$ equals the fracture toughness. If $\mathrm{K}_{\mathrm{I}}$ continues to increase, then the crack accelerates and produces the topographic features of mirror, mist, and hackle on the fracture surface. The fracture origin, the direction of crack propagation, and the local stress distributions prior to fracture may be determined from the fracture-surface topography of glass [12]. The crack branches and a macroscopic crack branching pattern forms after hackle production. P. Acloque first reported on the fragmentation test in 1956, since then, several studies have explored the relationship among tempered level, glass thickness, and fragment number [13-15]. However, conclusive results on the above-mentioned correlation remain lacking to date. Tandon and Glass [16] studied the control of the fragmentation behavior in stressed glass and reported that fragment size is inversely proportional to the square of the central tension and weakly depends on sample thickness. Mognato et al. [17] showed that fragment number is proportional to the surface CS and that particle density is generally independent of the glass thickness if the thickness is within 4-10 $\mathrm{mm}$. Kooi et al. [18] also used fractal geometry to characterize the macroscopic surface crack branching patterns in strengthened glass. They showed that the crack-branching coefficient is not related to the strength or the stress at fracture or 
even to the total stored tensile strain energy. However, the relationship among the residual stresses, fragments, and fractography of chemically strengthened glass remains unclear at present.

The current study investigated the effect of residual stress on the flexural strength and fractography of chemically strengthened thin aluminosilicate glass to gain new insights into their relationships. Results showed that high CS and low CT improved the flexural strength of chemically strengthened glass. However, the effect of residual stress was more complex on Weibull modulus than on strength. Transparent and opaque zones were also observed on the fracture surface of chemically strengthened glass. The relative thickness of the opaque zone ( $\left.\mathrm{d}_{\text {Opaque }} / \mathrm{d}_{0}\right)$, which is a constant in the same fracture zone, linearly decreased with increasing fracture zone. This result indicates that the stored elastic-strain energy was released with the number of transverse cracks.

\section{Experimental method}

The glass used in this study was a sodium aluminosilicate glass (Corning 2318, Corning Inc., NY). The square plate samples measured an average of $100 \pm 0.5 \mathrm{~mm}$ on an edge and an average thickness of $1.80 \pm 0.02 \mathrm{~mm}$. Ion exchange involved suspending disks of the glass in a molten potassium nitrate bath held at $420{ }^{\circ} \mathrm{C}$ for varying periods $(1 \mathrm{~h}, 3 \mathrm{~h}, 5 \mathrm{~h}, 7 \mathrm{~h}$, and $12 \mathrm{~h})$. After the ion exchange, the disks were removed, cooled, and then rinsed with deionized water. The CS, DOL, and CT of the samples were determined through birefringence stress measurement (FSM-6000 LE, ORIHARA, Japan). 
The modulus of rupture (MOR) was determined on an Instron universal testing machine. ROR biaxial flexure tests were conducted to evaluate glass strength under annealed and ion-exchanged conditions.

The biaxial flexure test fixture was designed in accordance with the British standard (BS EN1288-5:2000) and ASTM C1499-09 standard. The fixture comprised a support ring with a diameter of $90 \mathrm{~mm}$ and a concentric loading ring with a diameter of $18 \mathrm{~mm}$. Each ring had a radius of curvature of $2 \mathrm{~mm}$ and was fabricated from stainless steel. Silicone rubber sheets $(\sim 3.0 \mathrm{~mm}$ thick) were used to serve as a compliant layer between the sample and the support and load rings. Adhesive tape was applied to the compressive side of the sample to retain fragments for fractographic analysis. Twenty specimens were tested for each condition at a stress rate of $2.0 \mathrm{MPa} / \mathrm{s}$, and the loads to failure were used to calculate the strengths of the specimens. The strength distributions were analyzed using a conventional two-parameter Weibull approach [19-23]:

$$
\begin{aligned}
& P_{f, i}=(i-0.5) / n \\
& \ln \ln \left[1 /\left(1-P_{f}\right)\right]=\ln V+m \ln \left(\sigma-\sigma_{0}\right)-m \ln \sigma_{0}
\end{aligned}
$$

Where $P_{f}$ is the fracture probability, $n$ is the total number of the samples tested and $i$ is the sample rank in ascending order of failure stress. $\sigma_{0}$ is a scaling parameter, referred as a characteristic strength defined as the stress at which the $P_{f}$ is $63.2 \%, m$ is the Weibull modulus and $V$ is the normalized volume of the tested sample. By fitting a straight line to $\ln \ln \left[1 /\left(1-P_{f}\right)\right]$ as a function of $\ln \sigma$, the Weibull modulus $m$ is simply obtained from its slope and the scaling parameter $\sigma_{0}$ can be determined from the 
intercept.

Fractographic analysis was conducted on the samples to identify the types of failure origins that contributed to failure. Visual inspections of the samples determined the fragment patterns and whether or not the sample failed because of surface or volume flaws. Samples that failed under the load ring or from edge failures were identified. The fractured surface of the samples was investigated through scanning electron microscopy (SEM).

\section{Results and discussions}

The CS and DOL of the ion-exchanged specimens as function of exchange time at $420^{\circ} \mathrm{C}$ are shown in Fig. 1. DOL increases and CS decreases with exchange time. As the time increases, the potassium ions diffuse far into the surface, which increases the DOL. However, the CS decreases with exchange time because of the stress relaxation and increasing $\mathrm{CT}$ that need to be balanced by CS.

Figure 2 shows the typical load-deflection relationships for chemically strengthened thin aluminosilicate glass with different exchange times at $420^{\circ} \mathrm{C}$. The fracture load for annealed glass is very low $(\sim 500 \mathrm{~N})$. This result indicates that the flexural strength of annealed glass is lower than that of chemically strengthened glass. The fracture load for chemically strengthened glass varies with exchange time at $420^{\circ} \mathrm{C}$. However, the load-deflection curves become nonlinear with increasing load. Thus, large-deflection theory should be considered when analyzing the flexural strength of chemically strengthened thin aluminosilicate glass [7].

In this study, finite element analysis (FEA) was used to solve the large deflection 
problem. The insert of Figure 3a shows the finite element mesh of a square specimen commonly employed in ROR testing. The elastic properties of the specimen used in this study are $E$ (Young's modulus) $=70 \mathrm{GPa}$ and $v$ (Poisson's ratio) $=0.21$. Figure $3 \mathrm{a}$ shows the specimen center deflection as a function of the applied load for small (ASTM C1499-09) and large (FEA) deflection solutions. Deflection linearly varies when the load is lower than approximately $500 \mathrm{~N}$ but nonlinearly varies when the load exceeds this amount. This finding differs from that obtained when small-deflection theory was employed in the ASTM C1499-09 test. FEA using large-deflection theory fitted well with the experiment. Thus, large-deflection theory must be considered when analyzing the flexural strength of chemically strengthened thin aluminosilicate glass. Figure $3 \mathrm{~b}$ shows ROR stress as a function of applied load using small and large deflection solutions. The stress linearly varies when the load reaches approximately $500 \mathrm{~N}$ but nonlinearly varies when the load exceeds this amount. Figure $3 \mathrm{~b}$ shows that the stress versus load plot is nonlinear and the small-deflection theory can predict stresses that are two or more times higher than the actual stresses.

The failure stress (flexural strength) of annealed and chemically strengthened auliminosilicate glass was obtained on the basis of large-deflection theory (Figure 4). Figure 4a shows the cumulative fracture probability $\left(P_{f}\right)$ as a function of the MOR for raw glass and chemically strengthened glass. It can be seen that the MOR of chemically strengthened glass is higher than that of the as-received glass at the same fracture probability. The MOR $(\sigma 0)$ and Weibull modulus $(\mathrm{m})$ of annealed and chemically strengthened auliminosilicate glass was also obtained as shown in Table 1 . 
Therein, the MOR $\left(\sigma_{0}\right)$ of chemically strengthened glass for $1 \mathrm{~h}$ at $420^{\circ} \mathrm{C}$ is the largest ( 801 MPa), which may attributed to the largest CS for $1 \mathrm{~h}$. Increasing the exchange time reduces the $\operatorname{MOR}\left(\sigma_{0}\right)$, and $\operatorname{MOR}\left(\sigma_{0}\right)$ of $\sim 655 \mathrm{MPa}$ is measured for the $12 \mathrm{~h}$ exchange. This reduction in the MOR $\left(\sigma_{0}\right)$ with increasing exchange time is attributed to CS relaxation (Figure 1). However, the MOR $\left(\sigma_{0}\right)$ of chemically strengthened glass for $5 \mathrm{~h}$ is larger than that for 3,7 , and $12 \mathrm{~h}$. This result indicates that the $\operatorname{MOR}\left(\sigma_{0}\right)$ is affected by both CS and CT. To analyze the Weibull modulus of these glasses, two-parameter Weibull plots for annealed glass and chemically strengthened glass subjected to a ROR biaxial flexure test at a stress rate of $2 \mathrm{MPa} / \mathrm{s}$ are shown in Figure 4b. Annealed glass has the lowest Weibull modulus $(m=2.68)$, indicating that it also has the largest strength variability. Chemically strengthened glass for $5 \mathrm{~h}$ has the largest Weibull modulus $(m=32.95)$, which is more than three times that of chemically strengthened glass for $1 \mathrm{~h}(m=9.82)$. This result may attributed to the small depth of the stress layer in chemically strengthened glass for $1 \mathrm{~h}(\mathrm{DOL}=20 \mu \mathrm{m})$. Well-controlled edge machining leaves flaws within $20 \sim 30 \mu \mathrm{m}[24]$. The DOL of $\sim 20$ $\mu \mathrm{m}$ cannot ensure that these machining flaws are fully enveloped with the CS, thereby causing the small Weibull modulus. However, increasing the DOL may increase the CT and affect the strength and Weibull modulus.

Figure 5 shows the contours of the CS-CT-MOR and CS-CT-m diagrams of chemically strengthened glass. Large CS and low CT improved the flexural strength of chemically strengthened glass. However, CS should be balanced with CT to improve the Weibull modulus which indicates that the Weibull modulus of chemically 
strengthened glass is sensitive to its CS and CT[25].

The fracture pattern for raw glass and chemically strengthened glass with different exchange times at $420{ }^{\circ} \mathrm{C}$ was shown in Figure 6. For annealed glass (Figure 6a), many radial cracks propagate from the fracture origin (in the red circle) to the sample edges. However, compared with annealed glass, chemically strengthened glass has higher density of radial cracks and transverse cracks. With prolonging exchange time, the number of radial cracks remains fairly constant, whereas the numbers of transverse cracks continue to increase. This finding suggests that the CT affects transverse cracks[18]. Figure 7 shows the stress localization of the in-plane surface tensile stress for different deflections. When the deflection approaches or is above the specimen thickness, the tensile stress is no longer homogenous. As a result, a peak stress is generated opposite the load ring, and a failure occurs underneath the load ring which are consistent with the experimental results as shown in Figure 6. In addition, the stress wave along the radial direction from the origin may provide useful information on the transverse crack circles from the crack patterns.

To elucidate the mechanism underlying the formation of transverse cracks, the schematic fracture pattern of chemically strengthened aluminosilicate glass is shown in Figure 8. It can be seen that along one radial crack, more than five zones can be marked using the transverse cracks. We only analyzed the nearest five zones from the origin to predigest the problem. The mechanism underlying the transverse crack generation in our samples may be as follows: the subsurface mist hackle features are manifestations of the crack front going out of plane. These perturbations are 
suppressed when then nonplanarity of the crack front is small and the CT is low [18]. However, these perturbations can be extended to be perpendicular to the plane of the primary crack for glass with high CT. The relaxed CS can impede the growth of these cracks, and they breach the surface.

Figure 9a shows a typical image of the fracture surface for zone 1 of chemically strengthened glass. The fracture surface has two parts: transparent and opaque zones. However, this characteristic was not observed in the as-received glass. Therein, the transparent zone is related to the compressive surface during loading and the opaque zone corresponding to tensile surface. In Figure $9 \mathrm{~b}, \mathrm{~d}_{0}$ is the specimen thickness, $\mathrm{d}_{\text {Opaque }}$ is the opaque zone thickness, and $\mathrm{r}$ is the radius of fracture origin. In addition, dopaque is a constant in the same fracture zone. However, this constant decreases with increasing fracture zone (Figure 9c). This result indicates that the stored elastic strain energy was released with the number of transverse cracks.

Residual stress also affects the fracture origin. Such as stress can alter the shape of the mirror region and change the stress axis intercept for the $A_{m} / m$ line on a stress versus the inverse square root of the fracture mirror radius plot [26]. Figure 10 shows the radius of the origin zone as a function of exchange time (a) and CT (b) for chemically strengthened aluminosilicate glass. The red line in this figure is the fitting result. The radius of origin decreases with prolonging exchange time and can be described using a linear function. The radius of origin also decreases with the $\mathrm{CT}$, but the radius of origin-CT relation could be described using the following exponential function: 


$$
y=\exp \left(A x^{2}+B x+C\right)
$$

where $y$ is the radius of origin; $x$ is the CT; and $A, B$, and $C$ are constants, where $A=1.07 \pm 0.11, B=0.05 \pm 0.01$, and $C=-0.003 \pm 0.0004$.

As is well known, the mirror is the first type of surface to form and it is also the characteristic of slow-moving cracks[27,28]. The mirror is related to the velocity of transverse elastic waves in the glass and the critical stress to the cohesive strength of the glass. We speculate that the velocity of transverse elastic waves in the glass increases but the critical stress to the cohesive strength decreases with increasing CT. This phenomenon results in the small origin. A detailed investigation on the mechanism must be conducted. These results also indicate that CT does not linearly increase with exchange time.

$d_{\text {Opaquel }} / d_{0}$ as a function of the fracture zone from the origin for chemically strengthened glass with different exchange times at $420^{\circ} \mathrm{C}$ is shown in Figure 11 . $d_{\text {Opaque }} / d_{0}$ decreases with distance from fracture origin. The decreasing rate differs between specimens with different exchange times. This result indicates that the transverse cracks influence $d_{\text {Opaque }} / d_{0}$. The transverse cracks release the elastic strain energy and decrease $d_{\text {Opaque }} / d_{0}$.

Figure 12 shows the typical SEM images of continuous fracture surface of zone 1 for chemically strengthened glass $\left(420^{\circ} \mathrm{C}, 1 \mathrm{~h}\right)$. A small region of mist can be observed near the fracture origin. The mist continues as the crack moves to the right and expands across and into the section. With crack propagation, the mist converts to hackle near the compressive surface. Wallner lines and Hackle marks on the fracture 
surface reveal the crack propagation direction in each zone[29]. Twist hackle marks, which indicate that the tensile stress is tilted from the crack surface, are found near the macroscopic crack branching. These marks may be related to the large deflection of chemically strengthened glass during loading. The presence of a clear zone near the compressive surface indicates a relatively low crack velocity and a relatively low energy release rate $[30,31]$. In other words, the existence of the clear zone allows crack bifurcation by controlling the release rate of the stored elastic energy.

\section{Summary}

The large deflection problem on the flexure of thin chemical strengthened glass was solved through FEA. High CS and low CT improved the flexural strength of chemically strengthened glass. However, the effect of residual stress was more complex on Weibull modulus than on strength. Transparent and opaque zones were observed on the fracture surface of chemically strengthened glass. $\mathrm{d}_{\text {Opaque }} / \mathrm{d}_{0}$, a constant in the same fracture zone, linearly decreased with distance from fracture origin which indicates that the stored elastic-strain energy was released with the number of transverse cracks. These results provide useful information on the failure analysis of chemically strengthened thin glass.

\section{Acknowledgement}

The authors thank Judith Thei (Department of mechanical Engineering, Imperial College London) for the technical support and useful discussions. The research is part of a collaboration between Imperial College London and Beijing Institute of Aeronautical Materials. This work is supported by The National Natural Science 
Foundation of China (Grant No. 51402273).

\section{Figure captions}

Figure 1 Compressive stress (CS) and depth of stress layer (DOL) as function of exchange time for chemically strengthened thin aluminosilicate glass.

Figure 2 Typical load-deflection relationships for chemically strengthened thin aluminosilicate glass with different exchange times at $420{ }^{\circ} \mathrm{C}$.

Figure 3 (a) Specimen center deflection as a function of applied load: small (ASTM) and large (FEA) deflection solutions; The insert is shell element FEA model mesh. (b) ROR stress as a function of applied load: small (ASTM) and large (FEA) deflection solutions.

Figure 4 (a) Cumulative fracture probability (F) as a function of MOR for raw glass and chemically strengthened glass; (b) Two-parameter Weibull plots for raw glass and chemically strengthened glass tested using a ROR biaxial flexure test at a stress rate of $2 \mathrm{MPa} / \mathrm{s}$.

Figure 5 (a) Contours of the CS-CT-MOR diagram of chemical strengthened glass; (b) Contours of the CS-CT-m diagram of chemically strengthened glass.

Figure 6 Images of fracture pattern for raw glass and chemically strengthened glass with different exchanges time at $420{ }^{\circ} \mathrm{C}$. (a) Raw glass; (b) $1 \mathrm{~h}$; (c) $3 \mathrm{~h}$; (d) $5 \mathrm{~h}$; (e) $7 \mathrm{~h}$; (f) $12 \mathrm{~h}$.

Figure 7 Stress localization of the in-plane surface tensile stress for different deflections. (a) $1.0 \mathrm{~mm}$; (b) $1.9 \mathrm{~mm}$; (c) $2.9 \mathrm{~mm}$; (d) $3.9 \mathrm{~mm}$; (e) $4.4 \mathrm{~mm}$; (f) $5.0 \mathrm{~mm}$. Figure 8 Schematic fracture pattern of chemically strengthened aluminosilicate glass. 
Figure 9 (a) Typical image of fracture surface for zone 1; (b) Schematic fracture surface for zone 1; (c) Schematic fracture surface for zones 1 to 5.

Figure 10 (a) Radius of origin zone (r) as a function of the exchange time for chemical strengthened aluminosilicate glass, the red line is the fitting result; (b) Radius of origin zone as a function of the CT for chemically strengthened aluminosilicate glass, the red line is the fitting result.

Figure $11 d_{\text {opaque }} / d_{0}$ as a function of the fracture zone from the origin for chemically strengthened glass with different exchange times at $420^{\circ} \mathrm{C}$.

Figure 12 Typical SEM images of continuous fracture surface of zone 1 for chemically strengthened glass $\left(420^{\circ} \mathrm{C}, 1 \mathrm{~h}\right)$

\section{References}

[1] A.K. Varshneya (1994) Fundamentals of Inorganic Glasses, Academic Press, New York, pp. 339.

[2] S.S. Kistler (1962) Stresses in glass produced by nonuniform exchange of monovalent ions. J Am Ceram Soc 45:59-68.

[3] V. Tyagi, A. K. Varshneya (1998) Measurement of progressive stress buildup during ion exchange in alkali aluminosilicate glass. J Non-Cryst Solids 238:186-192.

[4] K.C. Chang, L. T. Tung, Y. C. Liu (2014) The mechanical properties of aluminosilicate glass with chemical strengthening. SID Symposium Digest of Technical Papers P66: 1226-1229.

[5] ASTM C1499-09, Standard test method for monotonic equilibrium flexural strength of advanced ceramics at ambient temperature, ASTM International, 100 Barr 
Harbor Drive, PO Box C700, West Conshohocken, PA, 19428-2959USA

[6] S. Timoshenko, S. Woinowsky-Krieger (1959) Theory of Plates and Shells, 2nd edition McGraw-Hill, New York.

[7] R. Kao, N.L. Perrone, W. Capps (1971) Large deflection Solution of Coaxial-Ring-Circular Glass Plate. J Am Ceram Soc 54:566-571.

[8] J.E. Ritter, Jr. K. Jakus, A. Batakis, N. Bandyopadhyay (1980) Appraisal of biaxial strength testing. J Non-Cryst Solids 38:419-424.

[9] S.T. Gulati, J.D Helfinstine, T. A. Roe (2002) Biaxial strength of ultrathin AMLCD glass substrates. SID 2002 Int. Sym., 3349-3351.

[10] B.R. Lawn (1993) Fracture of Brittle Solids, Cambridge University Press, Cambridge, United Kingdom.

[11] G.R. Irwin (1957) Analysis of stresses and strains near the end of a crack traversing a plate. J Appl Mech 24:361-364.

[12] M. Tomozawa (2003) Fracture of Glass. Annu Rev Mater Res 26:43-74.

[13] P. Acloque (1956) Deferred processes in the fragmentation of tempered glass. Proceedings of the 4th International Glass Congress 6279-6291.

[14] J. M. Barsom (1968) Fracture of tempered glass. J Am Ceram Soc 51:75-78.

[15] K. Akeyosh, E. Kanai (1965) Mechanical properties of tempered glass. Proceedings of the 7th International Glass Congress 14:80-85.

[16] R. Tandon, S. J. Glass (2005) Fracture Mechanics of Ceramics; Active Materials, Nanoscale Materials, Composites, Glass, and Fundamentals, Springer, pp. 77-92.

[17] E. Mognato, A. Barbieri, M. Schiavonato, M. Pace (2011) Thermally Toughened 
Safety Glass: Correlation between Flexural Strength, Fragmentation and Surface Compressive Stress. Glass Performance Days, 115-118.

[18] J.E. Kooi, R. Tandon, S.J. Glass, J.J. Mecholsky, Jr (2008) Analysis of macroscopic crack branching patterns in chemically strengthened glass. J Mater Res 23:214-225.

[19] W. Weibull (1951) A statistical distribution function of wide applicability. J Appl Mech 18:293-297.

[20] M. H. Krohn, J. R. Hellmann, D.L. Shelleman, C.G. Pantano (2002) Biaxial flexure strength and dynamic fatigue of soda-lime-silica float glass. J Am Ceram Soc $85: 1777-1782$.

[21] J. Zhang, D. Estevez, Y. Y. Zhao, L. Huo, C. Chang, X. Wang, R. W. Li (2016) Flexural strength and weibull analysis of bulk metallic glasses. J Mater Sci Technol 32:129-133.

[22] A. Khalili, K. Kromp (1991) Statistical properties of Weibull estimators. J Mater Sci 26: 6741-6752.

[23] K. Trustrum, A. D. S. Jayatilaka (1979) On estimating the Weibull modulus for a brittle material. J Mater Sci 14:1080-1084.

[24] M. Lindqvist, C. Louter (2014) Experimental study on glass edge machining flaw characterization. Eng. Fract. Mech., 127:56-70.

[25] Corning Incorporated (2010) Corning® Gorilla® Glass Chemical Strengthening Specification, New York.

[26] R.C. Bradt (2011) The fractography and crack patterns of broken glass. J Fail 
Anal And Preven 11:79-96.

[27] D. L. Iii (1981) Fracture strength and mirror size in a commercial glass ceramic. J Am Ceram Soc 64:82-86.

[28] G.K. Bansal , W. H. Duckworth (1977) Fracture stress as related to flaw and fracture mirror sizes. J Am Ceram Soc 60:304-310.

[29] E.K. Beauchamp (1995) Crack front stability and hackle formation in high velocity glass fracture. J. Am. Ceram. Soc. 78:689-697.

[30] D. Hull (1999) Fractography observing, measuring and interpreting fracture surface to topography, Cambridge University Press, Cambridge.

[31] J. H. Nielsen, J. F. Olesen, H. Stang (2009) The fracture process of tempered soda-lime-silicate glass. Eep Mech 49:855-870.

Table $1 \sigma_{0}$ and $\mathrm{m}$ of annealed and chemically strengthened auliminosilicate glass with different exchange time

\begin{tabular}{ccc}
\hline Exchange time $(\mathrm{h})$ & $\sigma_{0}(\mathrm{MPa})$ & $m$ \\
\hline 0 & 155 & $2.68 \pm 0.26$ \\
1 & 801 & $9.82 \pm 0.51$ \\
3 & 721 & $17.66 \pm 1.11$ \\
5 & 726 & $32.95 \pm 2.05$ \\
7 & 709 & $15.92 \pm 1.32$ \\
12 & 655 & $23.21 \pm 2.57$ \\
\hline
\end{tabular}




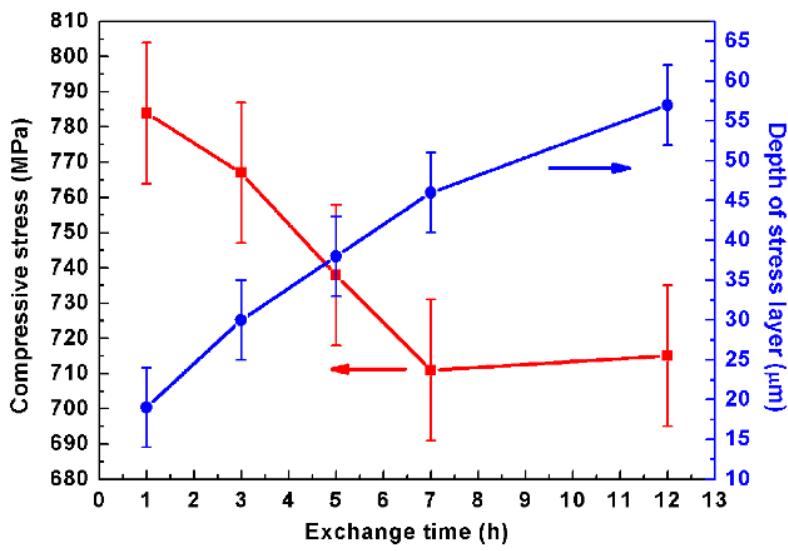

Figure 1

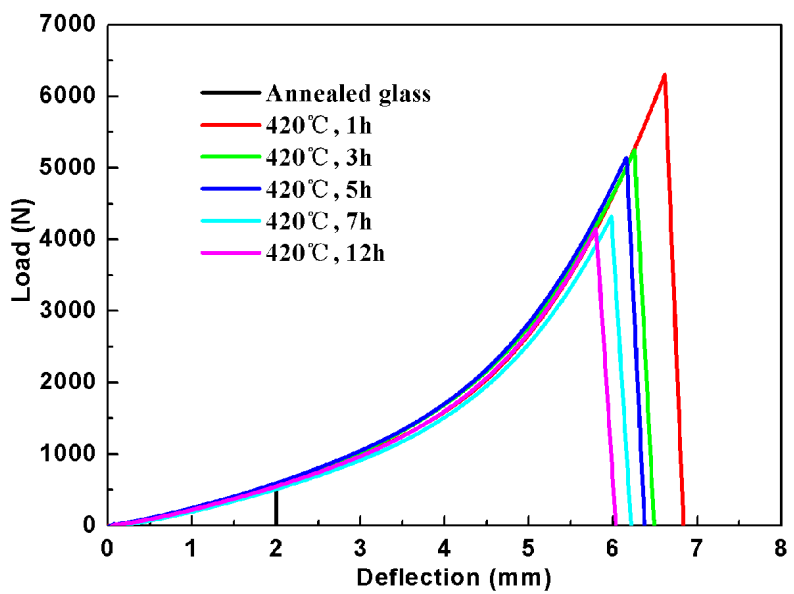

Figure 2
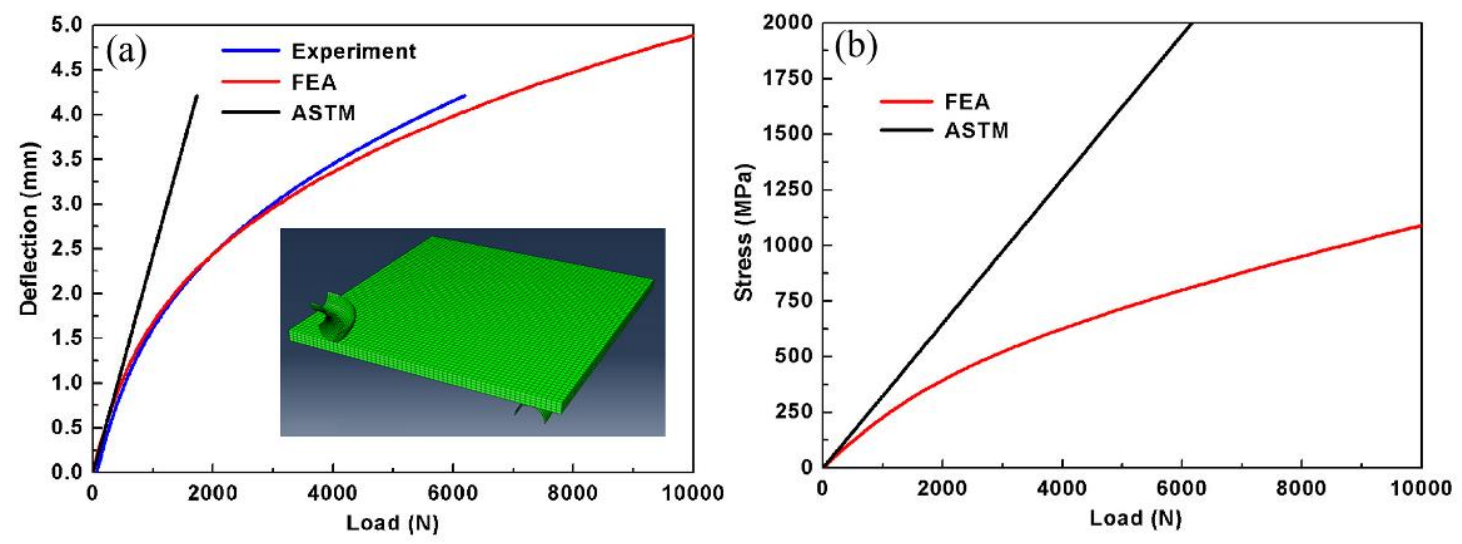

Figure 3 

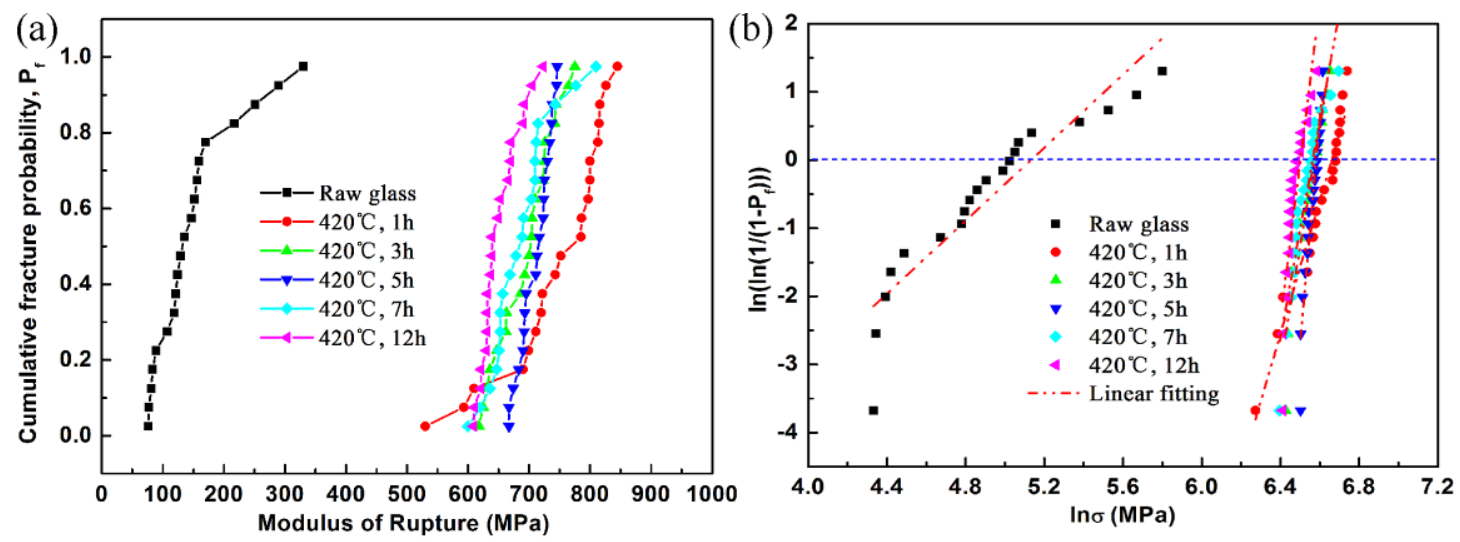

Figure 4

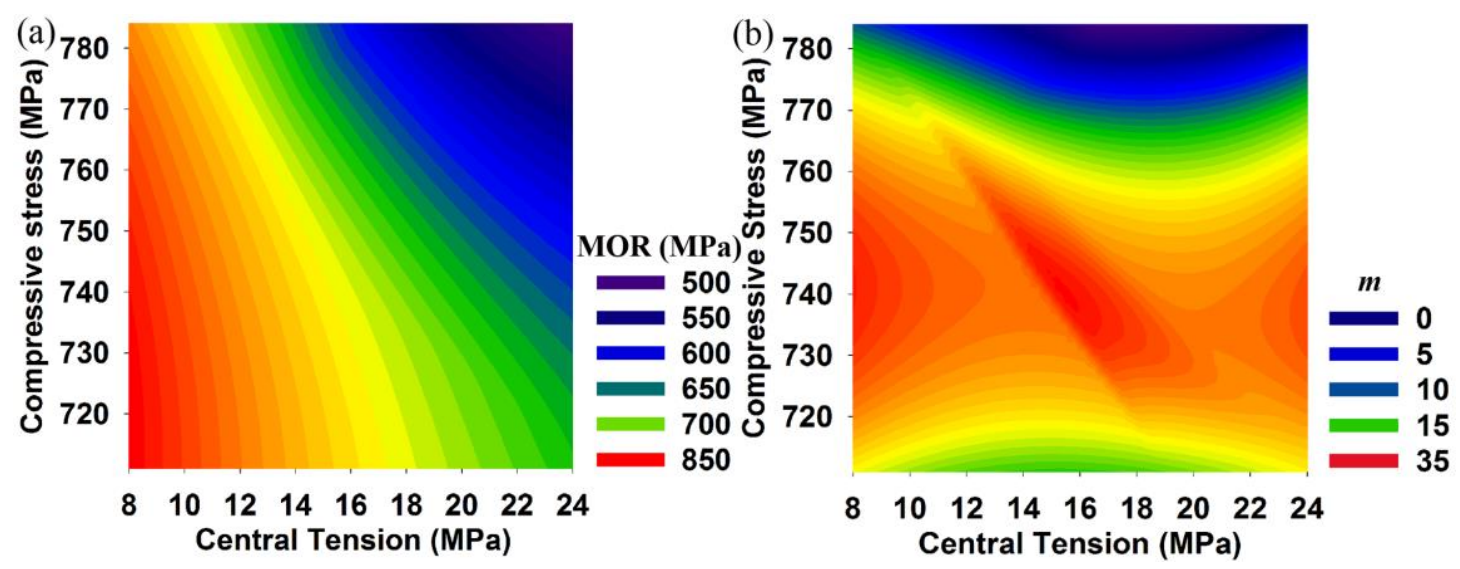

Figure 5 

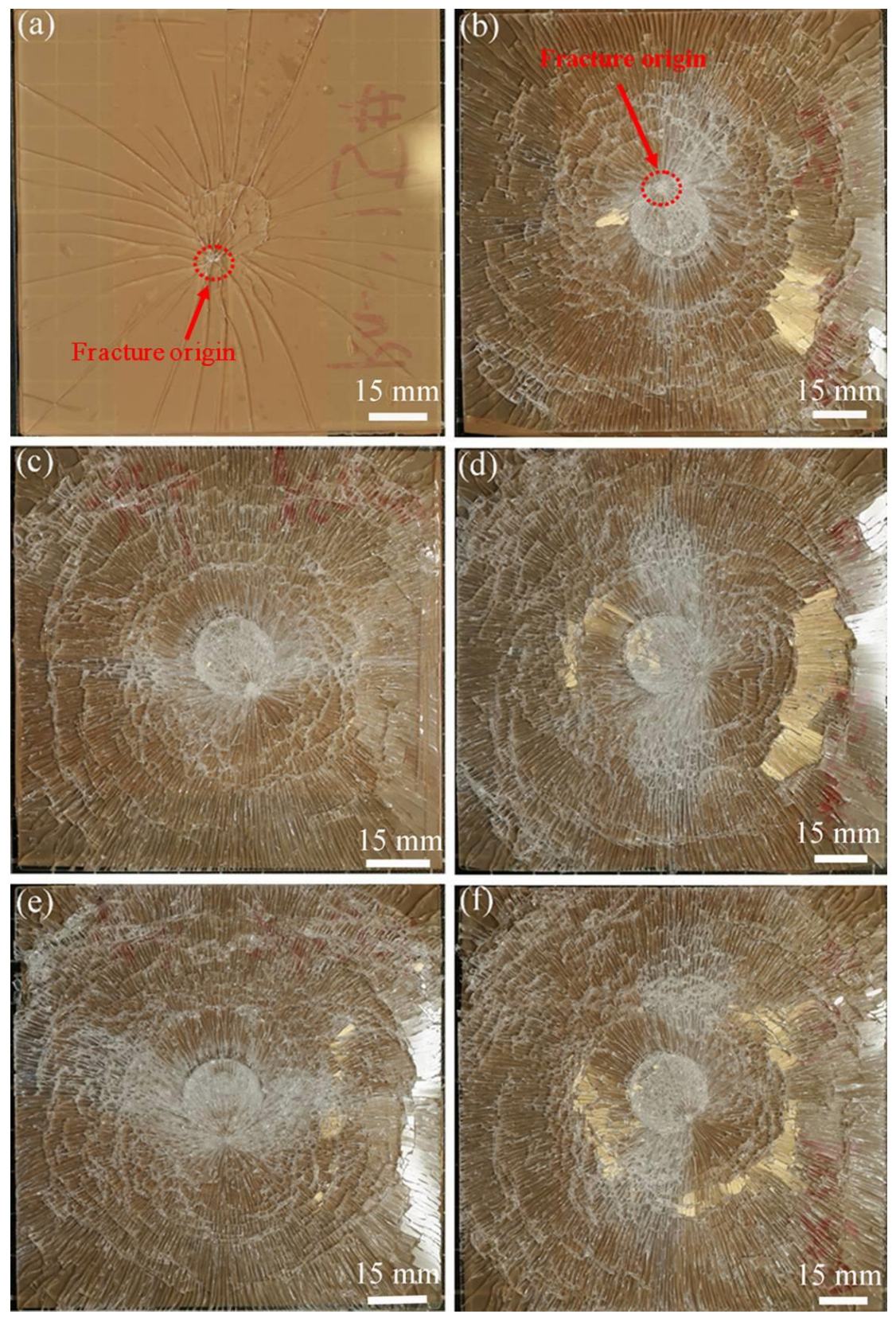

Figure 6 


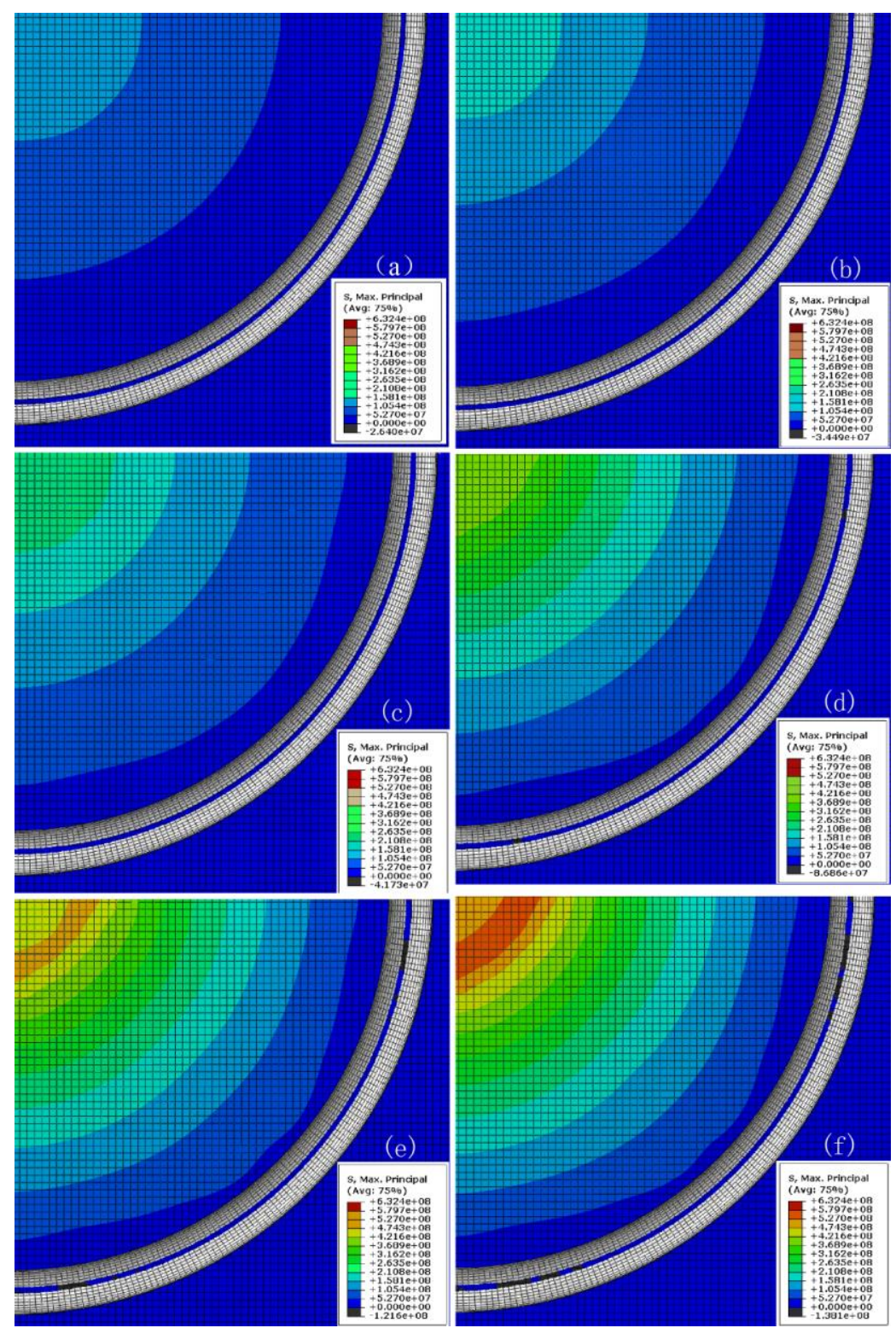

Figure 7

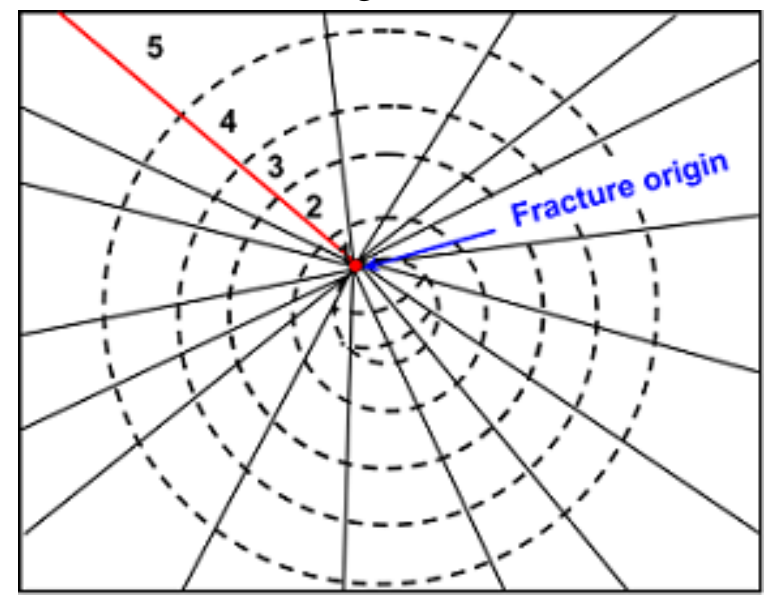

Figure 8 


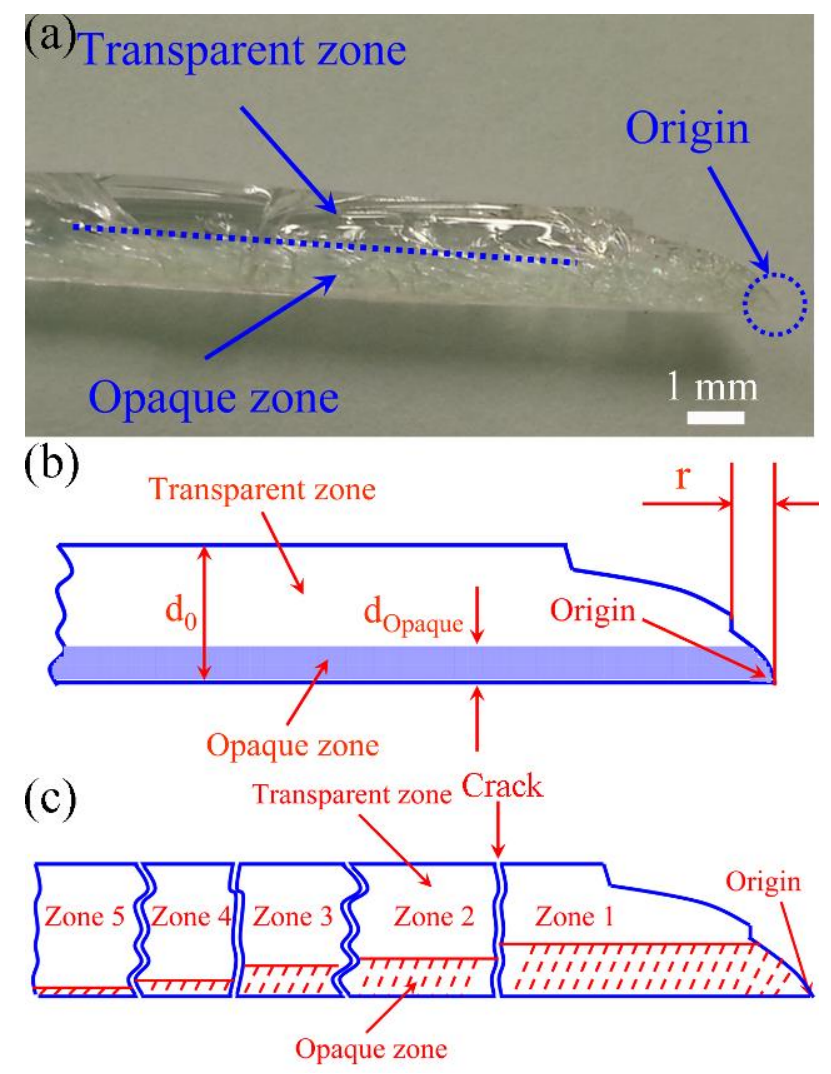

Figure 9
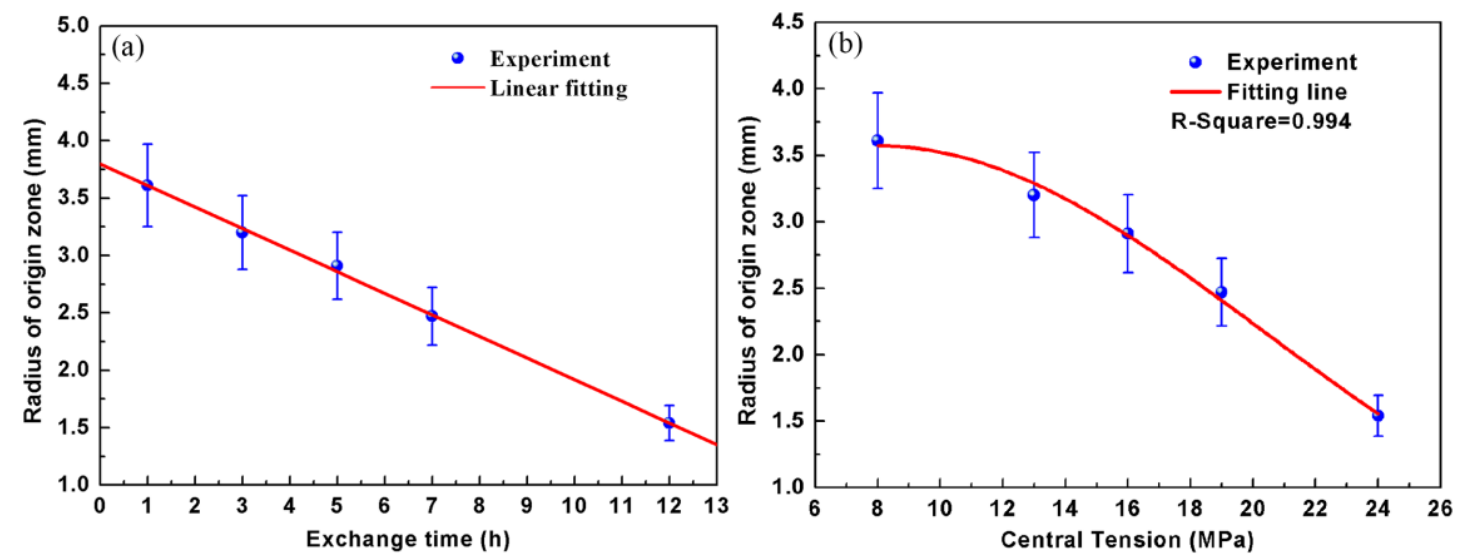

Figure 10 


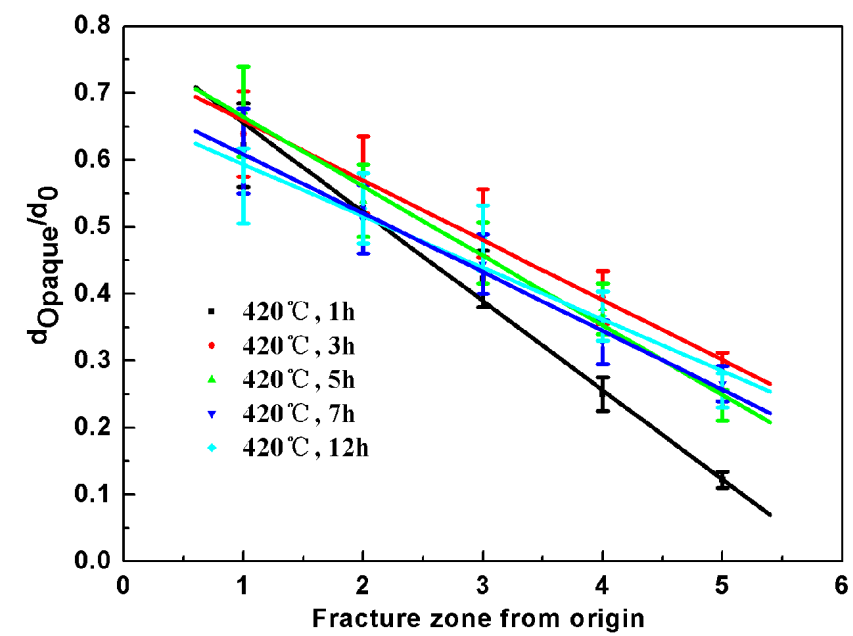

Figure 11

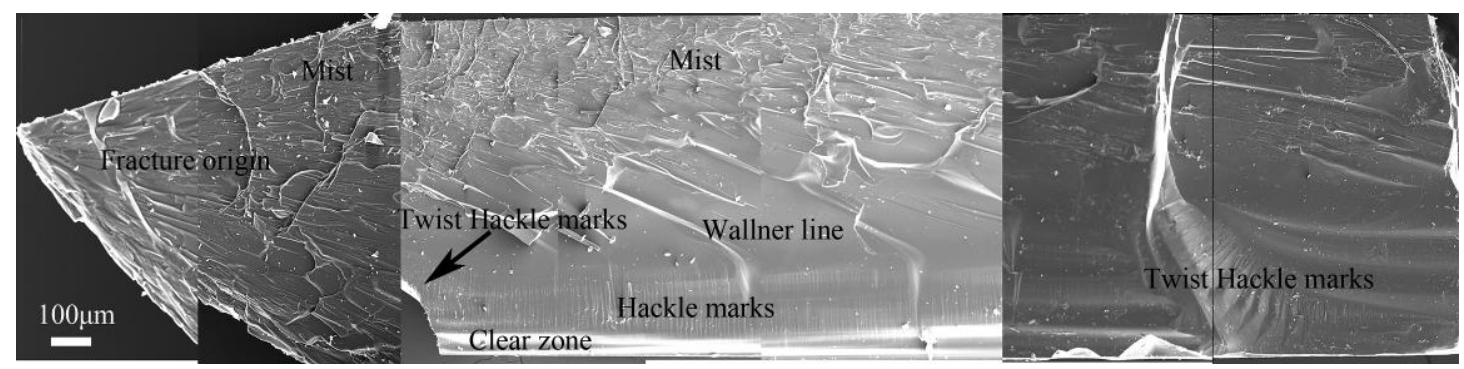

Figure 12 